


\title{
Yo (él) en "Muerte sin fin" de Gorostiza: la sustancia y la forma
}

\author{
Fernando Castaños
}

El presente artículoexpone una lectura analítica de un poema de José Gorostiza sobre el cual han hablado y escrito mucho y con gran admiración los escritores y los académicos en México. Se trata de un poema que Octavio Paz, para sintetizar su contenido y aprehender su constitución, identificó como "reloj de cristal de roca". Ésta es, quizá, la obra más importante del llamado grupo de los Contemporáneos, que, en su estética y en sus actitudes públicas, se opuso a la degradación y al abuso de lo nacional en la cultura de estado del régimen postrevolucionario de nuestro país, y al hacerlo abrió a los intelectuales horizontes de independencia frente al poder gubernamental.

Palabras Clave: poesía, "Muerte sin fin", José Gorostiza, Contemporáneos, muerte.

The present paper presents an analytical reading of José Gorostiza's poem on which writers and academics in Mexico have spoken and written extensively and with great admiration. It is a poem that Octavio Paz, to synthesize content and grasp its constitution, identified as "rock crystal watch." This is perhaps the most important work of a group called the Contemporáneos, which, in its aesthetic and its public attitudes, opposed to the degradation and abuse of the nationalism in the culture of post-revolutionary regime of México, and in doing so opened the intellectual horizons, independent from government power.

KEYWORDS: poetry, “Muerte sin fin”,José Gorostiza, Contemporáneos, death.

Fecha de recepción: 12 de octubre de 2013

Fecha de aceptación: 7 de enero de 2014 

Fernando Castaños

Universidad Nacional Autónoma de México

Instituto de Investigaciones Sociales

\section{Yo (él) en "Muerte sin fin"1 de Gorostiza: la sustancia y la forma}

Escrito desde el asombro que causa advertir el dinamismo del vocablo "muerte", este poema merecedor de admiración mayúscula escenifica una conversación que es un monólogo, la exposición de una tesis sobre la materia, la vida y la conciencia: devenir hacia la forma es su ser. Está precedido de tres proverbios bíblicos y consta principalmente de dos silvas extensas con versos libres intercalados, las cuales están separadas por un conjunto de estrofas seguidillas que hacen eco del hai-kú y secundadas de cuatro series de octosílabos. Las silvas tienen, cada una, un clímax de pasión mística asociada con la tesis: una confirmación y una renuncia. El interludio canta el solaz del alma que contempla y, a la vez, ratifica la voluntad de razonamiento de quien sostiene la tesis, una proyección del propio poeta. Él descifra, así, las correspondencias del epígrafe y enmarca el drama que significa comprender su teología. El epílogo asume las consecuencias de la tesis y de la renuncia. En la

${ }^{1}$ En nuestro país, han tratado acerca de este texto, Alfonso Reyes, Alí Chumacero, Evodio Escalante y David Huerta, entre otros; estudiosos de la literatura, como Guillermo Sheridan y Tarcisio Herrera; y autores que son escritores y estudiosos de la literatura, como Vicente Quirarte. Lo han considerado también filósofos, como Jaime Labastida y Humberto González Galván, al igual que filólogos y lingüistas, como Edelmira Ramírez y Margarita Palacios. Todos lo han valorado en forma superlativa. El poema es relativamente poco conocido fuera de aquí; pero quienes lo han comentado en otros países, como sus traductores Mordecai Rubin, estadounidense, y Fernand Verhesen, belga, lo han comentado de manera igualmente elogiosa. 
versificación, el autor reconoce su tradición y su circunstancia; en el planteamiento, se presenta como interlocutor de la filosofía universal. El texto, en consecuencia, comparte rasgos de una pluralidad de géneros. Aún así, su esencia es la de la poesía, que nos pone en presencia de la revelación de la palabra.

Pienso que contar con esta lectura en un texto publicado en una revista académica ${ }^{2}$ puede ser de utilidad, no sólo para los investigadores del discurso interesados en los asuntos a los que aludo en algunas de las notas de pie de página, en particular la segunda, sino igualmente para los estudiosos de la cultura interesados en el pensamiento y el arte latinoamericanos. Suscito y respondo preguntas que no han sido planteadas anteriormente, al menos no en la perspectiva que lo hago, por ejemplo, acerca del carácter mismo del poema. Asimismo, al destacar ciertas propiedades de su factura y determinados rasgos de su contenido, no sólo profundizo algunas conexiones entre la escritura de Gorostiza y la literatura y la filosofía universales que han sido señaladas por otros, sino que muestro algunos vínculos que no habían sido indicados. (En parte lo hago en el cuerpo del texto y en parte en otras notas de pie de página, para conservar los tempos y los ritmos de la lectura.)

El título del poema, "Muerte sin fin", es una invitación a presenciar a alguien que busca cantar lo que justo antes no podía ser dicho, un llamado casi, a asistir a la entrega imperiosa de alguien que se aventura a trascender los límites de su lenguaje. La palabra "muerte", que en su primera acepción nos remite a un proceso con el que concluye una trayectoria, la de la vida, es aquí el núcleo de una frase que niega una determinación;

\footnotetext{
${ }^{2}$ Éste es, con algunas adiciones, un texto presentado en el seminario de investigación ESP 6941 del Departamento de Literatura y Lenguas Modernas de la Universidad de Montreal, el 14 de marzo de 2008. Lo que he agregado es de dos órdenes. Se trata, por una parte, de observaciones que no incluí en la presentación para mantener su duración dentro de lo razonable; consta, por la otra parte, de respuestas a comentarios que Monique Sarfati-Arnaud y Javier Rubiera hicieron entonces, como parte de un diálogo con diversos participantes. Agradezco al departamento la invitación a exponer en el seminario y a todos los colegas sus aportaciones, que desafortunadamente no podría recoger cabalmente por ahora. Este trabajo forma parte de una serie de cuatro estudios sobre textos literarios, dos de los cuales ya han sido publicados: "Locos, muertos y ánimas en Pedro Páramo: los lugares de sus voces como rasgos de identidad" y "Tú, llama Hamlet a sí: una reflexión sobre las transposiciones pronominales" (El "tercero": fondo y figura de las personas del discurso, R. Montes y P. Charaudeau (coord.), 45-55, 2009.
} 
esta palabra que, en su segunda acepción, denota el punto de llegada del proceso, es empleada aquí para referir un camino que no tiene destino.

“¿Por qué el sustantivo que entraña una meta seguido de la construcción adverbial que niega cualquier acotamiento?”, se pregunta uno. Al causar que nos detengamos así, nos hace ver los otros rasgos de la palabra "muerte" en su acepción de proceso, apenas adumbrados en el trasfondo de lo que se dice con ella normalmente: movimiento, dirección, origen. Lo mismo ocurre con los rasgos secundarios en su acepción de resultado: rigidez, quietud, descanso. Se asoma también lo que generalmente viene con la muerte, y que, sabemos, algún día habremos de enfrentar: el dolor, la impotencia, la destrucción.

Si la sustancia de la palabra "muerte" se nos muestra cuando a ésta se yuxtapone la frase adverbial "sin fin", la incitación a observarla se repite, como en un fractal, por obra de la unión entre las palabras de esa frase, "sin" y "fin". Por diferir su pronunciación en el mínimo posible, el sitio donde silban la "s" y la "f", parecen una eco de la otra, y por un momento casi lo son, pues ambas nos hablan de carencia; pero al siguiente instante la diferencia sutil entre ellas aparece ante nuestros ojos magnificada. La palabra "fin" nos remite a un ordenamiento, en el espacio o en el tiempo, a un antes y un después. En cambio "sin" nos remite simplemente a un vacío.

De esa manera, el título "Muerte sin fin" no sólo anuncia que se hablará de la muerte en el poema; al atraer el pensamiento hacia sí como frase contradictoria, hacia sus propiedades de oxímoron, nos enseña que hablar de la muerte es hablar del movimiento y la quietud, del origen y el destino, de la materialidad y la nada. Ello, ver cómo se iluminan los rasgos de sentido de la frase, no resta interés a lo que se aludirá con la frase; más bien, se incrementa nuestra atención, de manera que podamos considerar, a la vez, las palabras que refieren y lo referido por ellas. En efecto, nos estamos preguntando también: “¿Quién o qué es lo que sigue muriendo siempre?"

En este estado de alerta, encontramos como epígrafe tres proverbios bíblicos. Ellos provienen de la sección acerca de la excelencia y la eternidad de la sabiduría en el libro sagrado:

Conmigo está el consejo y el ser; yo soy la inteligencia; mía es la fortaleza $(8,14)$. 
Con él estaba yo ordenándolo todo; y fui su delicia todos los días, teniendo solaz delante de él en todo tiempo $(8,30)$.

Mas el que peca contra mí defrauda su alma; todos lo que me aborrecen aman la muerte $(8,36)$.

Por los conocimientos que tiene de las enseñanzas provenientes de la religión católica repetidas en nuestras tradiciones, independientemente de la fe que profese, y aún si esos conocimientos son escasos, cualquier mexicano entiende que la primera persona del primer y el tercer proverbios, el yo que habla, es Dios. Sabe también que quien los está citando se identifica con el yo del segundo, donde Dios es la tercera persona, él. ${ }^{3}$ Uno se pregunta: ¿entonces de lo que va a hablar el poema es de la relación con Dios? ¿Es la necesidad de comprender esta relación lo que ha llevado a Gorostiza a desglosar los componentes dinámicos del sentido de la palabra? ¿Una relación, primero, de acercamiento a la sabiduría divina; después, de alejamiento del mandato divino?

Con esos antecedentes y tales inquietudes, empezamos a leer el poema, que consta de 795 líneas dispuestas en 39 páginas, y que está dividido en cuatro secciones que se distinguen de maneras que voy a ir indicando más adelante. La primera de esas secciones se compone de seis grupos de versos separados por espacios en blanco de dimensiones variables, el menor equivalente a cuatro líneas de texto y el mayor a quince. Cada grupo empieza en una nueva página, de manera similar a como ocurre con cada capítulo en un texto en prosa. Estos seis grupos ocupan 13 páginas y en total comprenden 300 versos.

El primer grupo empieza con una oración que tiene 117 palabras y está repartida en 21 versos, de los cuales los primeros nueve son los siguientes: ${ }^{4}$

\footnotetext{
${ }^{3}$ Aunque es obvio que así ocurre, explicar de forma precisa cómo se determina la referencia de cada uno de esos "yo" merece un esfuerzo especial, porque el proceso es revelador de los acoplamientos entre el sistema de la lengua y el sistema del habla; pero ello requiere un tipo de análisis y una reflexión teórica propios de otro tipo de artículo. Ésa es la materia del trabajo al que hago referencia en la nota 2.

${ }^{4}$ Para facilitar la ubicación de los versos, he numerado ciertas líneas con cifras entre corchetes. Al respecto de esto, como de la disposición espacial del poema, me refiero al formato del poema en la antología de Gorostiza. Lo que digo es esencialmente válido para otras ediciones impresas o electrónicas cuidadosas.
} 


\author{
LLENO de mí, sitiado en mi epidermis \\ por un dios inasible que me ahoga, \\ mentido acaso \\ por su radiante atmósfera de luces \\ que oculta mi conciencia derramada, \\ mis alas rotas en esquirlas de aire, \\ mi torpe andar a tientas por el lodo; \\ lleno de mí - ahíto- me descubro \\ en la imagen atónita del agua,
}

Como se ve, la extensión de la oración no diluye su contenido; más bien, lo concentra. La frase participia inicial "lleno de mí", estructura yuxtapuesta y, a la vez, subordinada, cumple varias funciones, además de reiterar el ritmo contundente del título (Tá-ta Tá Tá). Como estructura verbal independiente del verbo de la oración principal, y colocada antes de la oración, en ese lugar que también pueden tener las frases adverbiales, indica, y pone en común, las condiciones que habrá que tomar en cuenta al juzgar la validez de la proposición expresada por la oración principal, sin que ellas queden directamente en la mesa de discusión, sin ponerlas en tela de juicio, es decir, confiriéndoles el valor de supuestos. Como estructura nominal dependiente del sujeto de la oración, lo adjetiva, le atribuye propiedades; pero al mismo tiempo lo anuncia: es un medio de focalización temática, una manera de decirnos de qué tratará la oración - de la primera persona, del yo que dice que se ve al ver el agua.

Como en ciertas crónicas elaboradas, ese doble rendimiento de las participias iniciales, de preparar el terreno lógico y de enfocar el tema del mensaje, le permite a quien dice el poema hacer varios asuntos presentes a la vez y dar prominencia a uno, él mismo. Nos preguntamos, naturalmente, ¿quién es?

$\mathrm{Al}$ encontrar la oración "me descubro..." después de una serie de tres frases participias, el lector se pregunta también: ¿pero qué crónica del presente o qué reflexión sobre el registro del instante procura el yo de este poema? ¿Se trata de una confesión... o de una declaración? ¿Por qué, entonces, la mitigación, propia de una hipótesis en un texto expositivo? Al captar el sentido que toma el verbo en la estructura 
sintáctica que lo sostiene, en virtud del cual se identifica el sujeto con el complemento locativo, la duda se elabora: ¿es acaso una toma de conciencia previa a la confesión o la declaración, una auto observación o una introspección?

Justo entonces, vemos que el carácter elemental del agua es aprehendido con gran cuidado:

en la imagen atónita del agua,

que tan sólo es un tumbo inmarcesible,

un desplome de ángeles caídos

a la delicia intacta de su peso,

que nada tiene

sino la cara en blanco

Esta caracterización sugiere que quizá el texto sea una disquisición anterior aún, acerca de lo que hace posible el reconocimiento de sí. En suma, por arte de la sintaxis, a nuestra inquietud por enterarnos quién dice los versos, se añade la de saber cuál es el carácter del poema.

Paralelamente, por efecto de haberse ubicado el locutor como objeto directo y como objeto indirecto del verbo "llenar", y en un orden de ideas afín al análisis semántico del título, el lector se ha preguntado cómo puede algo contenerse a sí. Y ha encontrado, inmediatamente, la respuesta en el poema: en virtud del confinamiento por una fuerza superior, "un dios", con artículo indefinido y con minúscula. Es ella lo que lo configura.

La intensidad del pensamiento convocado por el poema, que casi nos desborda desde el primer momento, es modulada por los ritmos de los versos. Seguimos las pautas sintácticas de la lectura y respondemos a las claves semánticas del texto en un tempo marcado por la prosodia. Este primer grupo, como los demás de la primera parte, consta principalmente de versos de once sílabas, el metro de los sonetos renacentistas de Garcilaso de la Vega, el del “¡Ah de la vida!” de Francisco de Quevedo, el del "Idilio salvaje” de Manuel José Othón, el que también tendrá, después, "Piedra de sol" de Octavio Paz. Están acompañados de versos de siete, como ocurre en las "Églogas" del propio Garcilaso, en 
las "Soledades" de Góngora, en el "Primero sueño" de sor Juana y en el "Canto a un dios mineral" de Jorge Cuesta.

En "Muerte sin fin", esta combinación de endecasílabos y heptasílabos, la silva, es empleada de manera tal que en ocasiones quedan apareados dos heptasílabos (como en el "Primero sueño"): su música, que atraviesa el Siglo de Oro y la Colonia, que llega al México independiente y al posrevolucionario, recoge de esta manera ecos de los versos de catorce sílabas de Gonzalo de Berceo, los alejandrinos medievales del Mester de clerecía con los que empieza la poesía para ser leída, es decir, pronunciada por su propio público. El poema reconoce las genealogías y los legados de su tradición.

Uno de los principales efectos de combinar esos ritmos es dotar al poema de fluidez, lo que se percibe con claridad, paradójicamente, cuando la combinación llega a su mayor densidad, como en el siguiente fragmento con el que comienza la quinta oración, todavía dentro del primer grupo, y que también ejemplifica la potencia que pueden alcanzar las metáforas cruzadas en "Muerte sin fin":

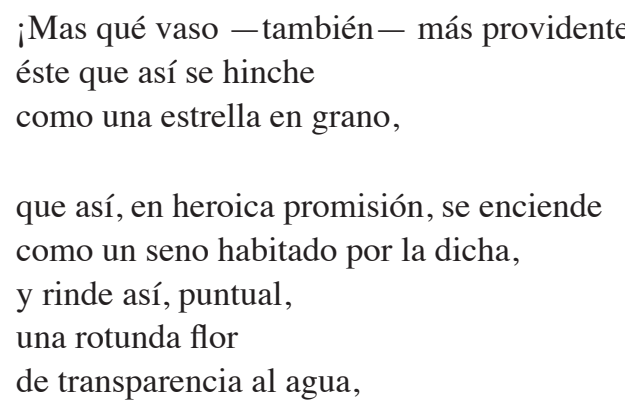

Pero, como si obedeciera al mismo impulso modernista de Rubén Darío, que lo llevó a abrir el repertorio métrico del soneto, Gorostiza introduce en la silva otros versos, sobre todo pentasílabos, como en el inicio de la oración anterior a la que acabo de citar, es decir, de la cuarta:

En la red de cristal que la estrangula, allí, como en el agua de un espejo,

El uso de los pentasílabos incorpora también, si bien apenas insi- 
nuados, efectos que caracterizan una forma de poesía surgida en otras latitudes y otros tiempos, el verso blanco de Marlowe, Shakespeare y Milton. El último par de versos en el siguiente fragmento, el $13^{\circ}$ y el $14^{\circ}$ del poema, un pentasílabo y un heptasílabo, tiene una resonancia como tal, como unidad de dos, equivalente a la del endecasílabo previo, aunque suma doce sílabas:

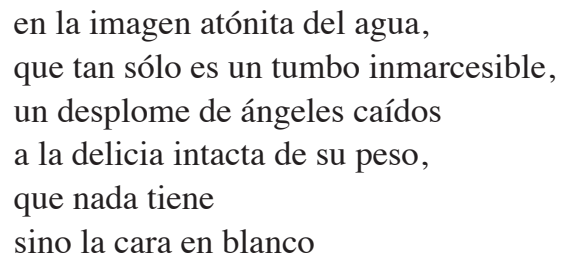

Como consecuencia de esa equivalencia, contamos el silencio después de "peso" como una sílaba más, lo oímos, lo que se logra en el verso blanco inglés por medio de la métrica de acentos.

De esta manera, Gorostiza, el autor del poema, reivindica una herencia secular, muestra que comparte las inquietudes recientes de otros americanos y nos hace ver que unas cadencias exploradas por poetas de distintas lenguas, que suponemos extrañas a la fonética del español, en realidad no nos son tan ajenas. Lo hace - retomemos el otro hilo- al tiempo que el yo del poema dice que al ver el agua uno se ve como el agua, que en el vaso alcanza plenitud.

Así, por gracia de la articulación precisa entre la sintaxis, la prosodia y la semántica, van mostrando, el autor, y diciendo, el yo, quiénes son. En su doble proceso de identificación, se van haciendo visibles los componentes de pensamiento que guardan los vocabularios de la muerte y la sustancia. Esta lectura del poema, esta realización que va cobrando conciencia de sí, está acompañada de preguntas del lector sobre el lugar desde el que habla el yo y sobre el carácter de sus parlamentos, que conducirán a otra, simple y precisa: ¿con quién habla?

De la misma manera, en los siguientes cinco grupos, cada palabra aporta átomos, cada frase forma moléculas, cada verso crea uniones estructurales. Se va construyendo así, desde adentro y desde abajo, un prisma a través del cual puede el lector mirar la luz analizada de la conciencia y en cuyas aristas puede ver también el brillo fugaz de la fe. 
Si nos asomamos a su interior, advertimos que unas caras se reflejan en otras y al reflejarse crean horizontes, abanicos, poliedros, laberintos: es un caleidoscopio de lenguaje.

En esos grupos, el yo del poema va exponiendo gradualmente, desglosando, una idea original y profunda: el ser, del cosmos, de la vida, de la inteligencia, es el movimiento constante hacia la forma, y el ser pleno es el que ha alcanzado la forma. Esta idea es acompañada, en cada grupo, por otra, a saber, por las siguientes:

\{2\} Quizá Dios (con mayúscula y sin artículo) sea un vaso de tiempo que nos sostiene.

\{3\} Eso no puede asegurarse porque el alma lo único que percibe es la alegría de la presencia de Dios.

$\{4\}$ Y el núcleo de esa alegría no es sino un sueño.

$\{5\}$ Es un sueño que se mira y sueña su repetición.

$\{6\}$ Y la inteligencia es una con su dios.

En otras palabras, el dios que concibe la inteligencia es, como ella, estéril; y el verdadero Dios es inefable. Estas ideas tienen una implicación que no es dicha; más bien, se muestra en el tratamiento, en la forma de ser del poema. Por los ecos de unos versos sobre otros, por sus matices, por el tono general que sus melodías y sus ritmos le confieren, el reconocimiento de la limitación de la inteligencia se nos presenta, se nos ofrece, como una prueba de que la conciencia es el producto de aquello que apenas adivina. Aquí, el poema es una loa a la grandeza de Dios, y así termina la primera parte: ¡ALELUYA, ALELUYA!

Esta alabanza jubilosa subyuga las dudas que se prefiguran en los grupos $\{3\},\{4\} \mathrm{y}$, sobre todo, $\{5\}:$ ¿si la conciencia se crea a sí misma, tiene Dios los atributos que nuestra teología le confiere? En otras palabras, con la expresión de emoción religiosa, el poema adquiere la tonalidad de una ratificación de fe, lo más cercano a un testimonio de conversión que es posible para alguien que ya es creyente.

En el trayecto hacia tal esbozo del carácter del poema, el lector ha encontrado parte de las respuestas a sus preguntas sobre su emplazamiento. Ha aprendido que las personas dentro del círculo del habla son tres, como los pronombres, como siempre. Sabe ya también que el yo que habla está 
en una habitación donde hay una silla, un calendario, un tintero, quizá el estudio del poeta. Esa resolución parcial de las interrogantes, precisamente por ser incompleta, ratifica la vigencia de éstas.

La segunda parte del poema es una serie de diez cuartetos, en la que se intercalan, después del tercero, el sexto y el noveno, tres pares de versos. Todos, los cuartetos y los pares, están compuestos por versos de cinco y siete sílabas. Si bien hay aquí, por esta métrica, una consonancia con los grupos de la primera parte del poema, la serie es claramente distinta, por la cardinalidad sistemática y por la carencia de endecasílabos. Además, el segundo y el cuarto verso de cada cuarteto riman entre sí.

Cree uno adivinar que, como en la comedia española, el cambio en la versificación señala un cambio de escena y de tono. Entonces, pensamos, ésta es una posible respuesta a nuestra pregunta sobre el carácter del poema: se trata de un libreto. ${ }^{5}$ Lo confirmaremos pronto; entre el penúltimo y el último cuartetos hay una línea con una palabra entre corchetes, que indica movimiento, es decir, una acotación escénica. ${ }^{6}$ La palabra es: "baile". Se pregunta uno si, en consecuencia, el yo del poema es un personaje: seguimos interrogando al texto y nos seguimos observando en nuestra lectura.

El espíritu de los cuartetos es el de la poesía corta japonesa, los haikú, que emulaba, o mejor, adoptaba, José Juan Tablada: captar un instante de percepción de la naturaleza y dar una expresión objetiva a la emoción que lo acompaña. Es casi con seguridad, advertirá el lector, que por eso da el autor al personaje las combinaciones de pentasílabos y heptasílabos: son como los tercetos de Tablada, con un verso adicional, con una coda, y ya había Tablada, en sus experimentaciones, descubierto que ese hai-ku castellanizado y mexicanizado era idóneo para objetivar la admiración de la naturaleza.

${ }^{5}$ La idea no parecerá descabellada, si se piensa que en sus primeros años de escritor Gorostiza creó obras de teatro sintético y si se advierte que, aunque las preocupaciones que las animaban eran sobre todo las de la denuncia social, al menos en la que aún se conserva, Ventana a la calle, se expresan ya dudas teológicas importantes (si bien en otro tono).

${ }^{6}$ Reforzarían la tesis una vuelta sobre temas visitados arriba, como la construcción de un escenario para el habla, y la consideración de temas que he dejado fuera de este artículo, como el valor de la iluminación en la representación. 
Para ilustrar la maestría con que se logran los objetivos de aligerar la lectura y mostrar el gozo del alma por la naturaleza sin hacer presente al alma, cito el séptimo cuarteto:

Sabe a luz, a luz fría, sí, la manzana.

¿Qué amanecida fruta tan de mañana!

La segunda parte tiene otros dos propósitos. Primero, nos muestra al personaje interpelando al agua, en el segundo verso del primer cuarteto. $\mathrm{Al}$ ser ella un interlocutor que no habla, y por lo tanto no tomará parte en el diálogo propiamente, éste tiene el valor del monólogo shakespereano. El personaje es alguien que puede ser observado aún en lo más íntimo de sus pensamientos, alguien que el autor puede observar y que, seguramente, ha estado observando durante el detenido proceso de escritura del poema. Se trata de un personaje que él, Gorostiza, nos muestra para que nosotros también lo podamos ver y oír.

Ver el poema como una escenificación conducirá a algunos lectores curiosos, acaso en las pausas de una segunda lectura, a recordar o a indagar que la palabra "proverbio" tenía entre sus acepciones aquella de obra dramática cuyo objeto es poner en acción una enseñanza repetida tradicionalmente.

En segundo lugar, los objetos cuya percepción se capta en los cuartetos son contrastados con el agua en los pares intercalados. Nos dicen que ésta es incolora, inodora e insípida. Parecerían expresar lo que diría alguien que dudara de los planteamientos iniciales del poema, los que le confirieron su gran impulso: ¿qué puede aportar a la comprensión de uno el compararse con el agua?

El personaje que habla y dice los grupos de versos de la primera escena, continúa hablando en la segunda, pero ya no es quien dice. Más bien, presta su palabra, la otorga, literalmente, a cualquiera que pudiera no estar de acuerdo con lo que ha dicho y se interesara en rebatirlo, quizá a alguno de nosotros, los lectores que pronunciamos las palabras. Entonces, sí, una de las pretensiones del texto es la de aproximarse a la verdad de la manera en que lo hace quien busca convencer, no sólo 
a su destinatario directo, sino a terceros. Se trata de un monólogo de razones, más que de motivos.

Después de este acto, de este periodo de solaz que anunciara el segundo proverbio, tenemos una nueva silva, de 378 versos agrupados en 13 grupos, que numeraríamos del 8 al 20, si continuáramos con la secuencia de la primera parte. Cada uno de estos grupos plantea, nuevamente, una serie de ideas que se unen en una aseveración principal. Por ejemplo, en el octavo grupo se afirma que al agua no le basta idolatrar al vaso donde encuentra su fulgor: quiere verse y oírse.

En el undécimo, dice que la forma se transfigura hacia lo informe. En el decimoquinto, que cuando ello ocurre, el hombre descubre que el lenguaje se sofoca. En el decimoctavo, que todo se consume cuando la forma pura alcanza la muerte. En el vigésimo, que el diablo es un ansia de trasponer esos límites.

Como en la primera parte, la energía de avance en esta tercera es la de la revelación semántica, la de los oxímoron y las metáforas cruzadas; su pulso es el de la música que integra cadencias seculares y ritmos modernistas; su articulación es producto de sintaxis y lógicas precisas, si bien complejas. Hay, aquí, guiños momentáneos a temas de otros poetas, como el de las responsabilidades paralelas del autor y el lector, de Baudelaire, o el de la relación entre el estilo y el contenido, de Mallarmé. Hay, ahora, señalamientos explícitos a los asuntos comunes con otros poetas, sobre todo los de sus contemporáneos mexicanos interesados en el formalismo y el surrealismo, y sobre todo los de Villaurrutia, como el de la "otra poesía" y el de los linderos entre el sueño y la vigilia.

Los grupos de esta tercera parte erigen otro prisma asombroso. En conjunto, recuperan una idea que se venía elaborando en la primera parte, al hacerlo descubren la duda que había quedado tapada por la loa a Dios y dan cuerpo a una tesis que es la contraparte de la conclusión del primer acto. La materia, la vida, la conciencia fluyen hacia la forma; su ser es un movimiento incesante hacia un punto estático. Por lo tanto, nunca alcanzan su perfección, y si la alcanzaran, se disolverían en la nada. Pero, entonces, este fluir, que es también la sustancia primaria y el modelo último de nuestro lenguaje, contraría el designio de Dios (que el mundo y la palabra sean). Luego, Dios ha muerto. 
Si nos asomamos al interior del segundo prisma, no encontraremos ya ni despliegues de figuras, ni sólidos geométricos, sino un coloide informe de rasgos de significado desorbitados. Si intentamos mirar el fondo, sólo adivinaremos un vórtice que, como un hoyo negro del cosmos, atrae los cuerpos, la luz, el pensamiento; que amenaza devorar todas las distinciones. El vacío que así se anticipa sería el infierno de quien había encontrado en Dios la plenitud del sentido; como en un análisis filológico que opusiera "diablo" (diábolo) a "símbolo", el lugar del diablo se revela como el sinsentido absoluto, y a ese lugar se dirige el yo del poema.

Como producto paralelo, en la segunda parte se reúnen y profundizan ciertas ideas que tienden a ocurrir separadas y que tendemos a considerar como provenientes de cosmovisiones paganas, aunque aún hoy tienen vigencia en distintos ámbitos de la sociedad mexicana. De éstas, en el poema la idea eje es que la vida y la muerte son una dualidad. Alrededor de ella se plantea: $\left(1^{\circ}\right)$ que la vida y la muerte forman ciclos, una siguiendo a la otra; $\left(2^{\circ}\right)$ que la vida surge de la muerte, y la muerte, de la vida; $\left(3^{\circ}\right)$ que al vivir se está muriendo y al morir se está viviendo.

A la ley del devenir de la sustancia gobernado por la forma y a la idea paralela de la dualidad vida / muerte las acompañan reconocimientos, en forma de ecos o gestos a los ecos, de la paradoja autorreferencial de Epiménides ${ }^{7}$ y del vértigo argumental de Parménides contra la unidad de la pluralidad. ${ }^{8}$ Hay, también alusiones a las alusiones de esas parado-

${ }^{7}$ Epiménides puso en aprietos a los lógicos griegos cuando afirmó que todos los cretenses eran mentirosos y no se podía aceptar lo que decían, porque él mismo era cretense. La paradoja que no podían resolver, y de la cual posteriormente se han derivado variantes simplificadas como "esta afirmación es falsa", se produce porque la expresión referencial apunta a sí misma. Las afirmaciones de Muerte sin fin acerca de la forma a veces se confirman y a veces son refutadas paradójicamente en sí mismas, porque para este poema el ser de la poesía y el del propio lenguaje están sujetos a las leyes de la forma.

${ }^{8}$ De acuerdo con el diálogo de Platón de mayor dificultad filosófica, cuyo título ha sido traducido como Parménides o De la forma y como Parménides o De las ideas, Parménides hace ver a Sócrates que el valor de la noción de forma radica en que conjuga la unidad y la pluralidad, pero que de esa conjunción resultan conclusiones absurdas. En torno a esta tesis central, por medio de un análisis detallado y exhaustivo sobre la lógica de la semejanza, pone en duda mayúscula nuestros principios ontológicos y epistemológicos. Su argumento principal es que, si decimos que dos objetos particulares son semejantes porque comparten la misma forma, entonces uno de ellos y esa forma 
jas en la prelación ontológica de la nada de Heidegger ${ }^{9}$ y, por supuesto, en la evolución recurrente de Nietzche. ${ }^{10}$

Plantear en el marco de esa ley y esas ideas la tesis de la muerte de Dios y representar el infierno que implicaría esa tesis es equivalente a aceptar la tesis y a decir que se acepta con conocimiento de sus consecuencias y en plenas facultades. ${ }^{11}$ Como acto de la voluntad, es un recuento, una declaración y una disposición última, como las que se profieren en el lecho de muerte. Se trata de una renuncia a la fe y de un rechazo al núcleo de la teología que proveyera el lenguaje para examinar la fe. Hay, no obstante, un reconocimiento a esa teología, una ex-

tendrán que ser semejantes porque comparten una forma, más pura que aquélla; pero esto conduce a una serie infinita, imposible. De aquí se deduce que la pluralidad es ilusoria, irreal. Los planteamientos de Gorostiza expresan el mismo tipo de reflexiones y les añaden una dimensión dinámica, como se ha señalado en el presente artículo. La profundidad y complejidad que resultan son inéditas. Al mismo tiempo, su conclusión es más modesta y más humana: no es que la diversidad del cosmos no exista, sino que la teología que le ha permitido apreciarla entraña una cosmogonía falsa.

${ }^{9}$ Parménides ponía en duda que pudiera afirmarse que algo no existe, porque tal afirmación sería acerca de ese algo, y si ese algo no existe entonces no se puede verificar ni refutar predicado alguno que se le atribuya (incluyendo el de la existencia), es decir, la predicación no tiene sentido. Heidegger, en una especie de continuación de este argumento, plantea que la negación lógica produce sentido cuando lo que se niega es algo que podría afirmarse positivamente y que, por lo tanto, la nada no se concibe como el opuesto del todo o como el opuesto de algo, ni tampoco como el opuesto de la existencia; más bien es un concepto primario, que no se deriva de otros, sino de ciertas emociones, en particular el miedo (o la angustia). Entonces, la reflexión filosófica acerca de la existencia, y de otros temas cardinales, no puede incluir propiamente la consideración de ese concepto, el de la nada, sino que debe suponerlo. En la primera silva de Muerte sin fin, el ser se distingue de la nada porque se orienta hacia la forma; en la segunda, la nada es el origen al que regresa el ser.

${ }^{10}$ Como lo ha señalado César González, la teología cristiana crea un tiempo lineal cuando pone en su centro la vida irrepetible de Jesús. Nietzche y Gorostiza oponen a ella una cosmogonía de ciclos.

${ }^{11}$ Sería un ejemplo de soberbia soslayar que Gorostiza coincide con Nietzche, no sólo en oponer la cosmogonía cíclica a la teología lineal, sino también en plantear la duda teológica en función del fracaso del proyecto divino, y sería una insensatez decir que las coincidencias son casuales. Gorostiza reconoce la profundidad y la originalidad del pensamiento de Nietzche al expresar la inexistencia de Dios como una muerte, en lugar de una ausencia inicial, que es la forma común del planteamiento. Pero sería, no un abuso, sino una mera ocurrencia, sugerir que las actitudes de Gorostiza convergen con las de Nietzche, y que el poeta, como el filósofo, se ha empeñado en un cuestionamiento muy inteligente de la razón. El carácter, las pretensiones de validez y la conclusión de "Muerte sin fin" son signos inequívocos y convergentes de una valoración positiva del razonamiento. 
presión de gratitud por ese lenguaje, y en ese lenguaje. La tercera parte termina como la primera: ¡ALELUYA, ALELUYA!

Eso es lo que Gorostiza, con el título y los proverbios, anunciaba que necesitaba decir. Eso es lo que el yo del poema asume. Esto es lo que se nos ofrece como lectores, para que lo juzguemos cual argumento y nos observemos al juzgarlo. Esto es lo que hemos pronunciado como público, para que lo oigamos cuanto canto y al oírlo veamos a la forma cobrar conciencia de sí. Es, ello, lo que requería los desgloses dinámicos de la muerte y de la sustancia.

Tenemos un poema que sólo pudo haberse escrito en el siglo Xx. Como en las pruebas de algunos teoremas matemáticos, antes la humanidad no contaba con un acervo que lo hiciera posible. Tenemos una obra que logra algo muy raro, algo que pocas veces se proponen los literatos: dos clímax. ${ }^{12}$ Seguramente, ambos, el de la confirmación y el de la renuncia, sólo podrán experimentarse plenamente, en su singularidad y en su unidad, al leer todo el poema. Pero quizá una selección de algunos fragmentos de la primera parte y algunos de la tercera pudiera brindar aquí un indicio de su efecto. De la primera, yo escogería los siguientes:

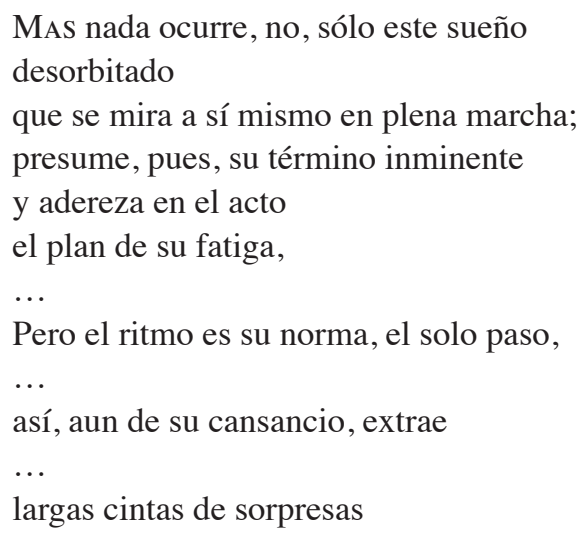

${ }^{12}$ Por esta razón, en ocasiones se han suscitado controversias irresolubles sobre Muerte sin fin; algunos afirman, por ejemplo, que se trata de un poema optimista, mientras que otros afirman que es uno pesimista; para algunos es místico y para otros blasfemo. En tales debates, es común que uno de los sustentantes trate de aquello que conduce al primer clímax como si lo estuviera haciendo de todo el poema y otro de aquello que conduce al segundo clímax de la misma manera. Por el desfase temático, sus argumentos resultan inconmensurables (aunque ambos pueden ser parcialmente válidos). 
hasta que - hijo de su misma muerte,

siente que su fatiga se fatiga,

$\cdots$

y sueña que su sueño se repite,

..

muerte sin fin de una obstinada muerte,

¡OH INTELIGENCIA, soledad en llamas, que todo lo concibe sin crearlo!

Finge el calor del lodo,

...

y permanece recreándose en sí misma, única en Él, inmaculada, sola en Él, ...

y se mantiene así, rencor sañudo, una, exquisita, ...

con Él, conmigo, con nosotros tres; como el vaso y el agua, sólo una que reconcentra su silencio blanco en la orilla letal de la palabra

..

¡ALELUYA, ALELUYA!

De la segunda parte, éstos:

Pero el vaso

- a su vez-

cede a la informe condición del agua

a fin de que - a su vez - la forma misma,

la forma en sí, que está en el duro vaso

sosteniendo el rencor de su dureza ...

se pueda sustraer al vaso de agua;

un instante, no más,

cuando la forma en sí, la pura forma se abandona al designio de su muerte 
PORQue el hombre descubre en sus silencios

que su hermoso lenguaje se le agosta

en el minuto mismo del quebranto,

cuando los peces todos

...

deshacen su camino hacia las algas;

cuando todo - por fin - lo que anda o repta

y todo lo que vuela o nada, todo,

se encoge en un crujir de mariposas,

regresa a sus orígenes

y al origen fatal de sus orígenes,

y todo cuanto nace de raíces,

desde el heroico roble

hasta la impúbera

menta de boca helada;

...

se esconden en sus ásperas raíces

y en la acerba raíz de sus raíces

y presas de un absurdo crecimiento

se desarrollan hacia la semilla,

cuando las piedras finas

y los metales exquisitos, todos, regresan a sus nidos subterráneos

por las rutas candentes de la llama,

ay, ciegos de su lustre,

ay, ciegos de su ojo,

cuando la forma en sí, la forma pura,

se entrega a la delicia de su muerte

...

mientras unos a otros se devoran

al animal, la planta

a la planta, la piedra

a la piedra, el fuego

al fuego, el mar 
donde el sueño no duele,

donde nada ni nadie, nunca, está muriendo

y solo ya, sobre las grandes aguas,

flota el Espíritu de Dios que gime

con un llanto más llanto aún que el llanto,

¡ALELUya, ALELUya!

[726]

En la cuarta parte del poema hay, nuevamente, otra versificación. Consta de cuatro grupos. Los tres primeros están formados por 14 versos cada uno, todos de ocho sílabas, uno de los metros más populares, el de las coplas, el del corrido. Después de ellos hay una acotación escénica, la misma, repetida, de la segunda parte: "baile". Adquiere ahora mayor fuerza, pues nos hace recordar que en la Edad Media en Europa, y sobre todo en España, muchas veces se empleaba la danza para representar lo diabólico o los efectos de lo diabólico.

Finalmente, hay un grupo de seis versos, igualmente octosílabos. Esta parte es una especie de epílogo. Resume la grave pasión de la renuncia, retrata lo que quedó y narra las consecuencias, el desenlace. Al empezar, el personaje dice "Tan-tan”, como para hacernos oír a los lectores el toquido de una puerta que él está oyendo. Pregunta, entonces, “¿quién es?” Y responde, como prestando su voz a alguien que estuviera detrás de la puerta: "el diablo". Termina pintando a la muerte como un personaje mundano, y nos revela que es ella la otra persona en su círculo de habla:

\footnotetext{
Desde mis ojos insomnes

mi muerte me está acechando, me acecha, sí, me enamora con su ojo lánguido.

¡Anda, putilla del rubor helado, anda, vámonos al diablo!
}

Cuando leo estos versos, yo no puedo dejar de ver, en la imaginación, grabados como los de José Guadalupe Posada o diablos y calaveras de papel maché como los que se venden en México al terminar la Semana Santa para hacerlos explotar con fuegos artificiales, y que genéricamen- 
te llamamos "Judas". ${ }^{13}$ Tampoco puedo dejar de sonreír al pensar en el estudio del poeta que se convierte, como en un sueño, en la habitación donde está su lecho de muerte y, luego, en la esquina de un salón de baile, quizá como los de la colonia Obrera de la ciudad de México.

Es claro que ver esas imágenes u otras es algo que Gorostiza deja a cada lector; él prefirió no emplear ninguna directamente. ${ }^{14}$ De cualquier modo, se queda uno cavilando si el libreto no será más bien el de una ensoñación, en la que el personaje se desliza casi imperceptiblemente de un espacio a otro.

Se completan aquí las claves que faltaban para definir el texto. El personaje es una proyección del poeta. Es como ve él que sería al llegar a la muerte. Es la manera que tiene de poner frente a sí la confesión que hará, no a Dios, sino a la propia muerte, lo que será confesarse ante sí mismo. Es la forma que ha logrado dar a su renuncia a la fe, para poder juzgarla como si fuera la de una tercera persona y como la juzgaríamos otros.

Con esta escenificación, José Gorostiza nos dice: "Soy un mexicano del siglo xx, que reconoce su tradición teológica y ama su tradición poética; que se interesa en la poesía y el pensamiento universales; que se dispuso a pensar por cuenta propia, y que ha dejado de creer en Dios. Aquí estoy. Aquí están mis razones y mis emociones." Lo dice de la mejor manera en que pueden ser mostrados el acervo y el potencial de significados de la lengua: por medio de la poesía.

${ }^{13}$ Como lo argumenta Claudio Lomnitz en Idea de la muerte en México, la familiaridad con la muerte, representada por un esqueleto, en ocasiones mordaz, muchas veces jocoso y generalmente juguetón, es una de las tres grandes construcciones simbólicas que hacen presente el pasado atávico y dan cuerpo al contrato social de los mexicanos, es decir, un "tótem". (Según él, las otras son la filiación con la "virgen morena" y el compromiso de Benito Juárez con la razón y la ley.)

${ }^{14}$ Cabe pensar que evitar tales figuraciones fue una decisión del poeta y que resultó de una reflexión seria, que expresa una toma de posición; no podría explicarse en función de alguna obediencia a una poética que rechazara de manera general plasmar lo que se mira o se imagina, y menos como una omisión involuntaria. Más aún, parece hacer deliberadamente eco de planteamientos de Cuesta sobre el abuso del nacionalismo y contra el uso de estereotipos en el arte posrevolucionario, los cuales, se ha difundido con cierta amplitud, fueron cuestionados por Paz en sus inicios como escritor y después defendidos por él mismo, precisamente al elogiar Muerte sin fin. Para él, se revelaba como más valioso explorar las profundidades del alma mexicana y las opciones de sentido del ser humano universal que reeditar los signos de lo popular que se apropiaba el régimen de partido hegemónico. 


\section{REFERENCIAS}

AA. VV., José Gorostiza (Testimonios de Alfonso Reyes, Jorge Cuesta, Xavier Villaurrutia, Octavio G. Barreda, Jaime Torres Bodet, Octavio Paz, Salvador Elizondo, Ramón Xirau, José Alvarado y Gabriel Zaíd), México, Fondo de Cultura Económica, 1974.

Baudelaire, Charles, "Au lecteur", en Fleurs du mal [1857], Paris, PouletMalassis ("Al lector", en Las flores del mal, Madrid, Cátedra, 2008).

Berceo, Gonzalo de, "Milagros de Nuestra Señora", <www.cervantesvirtual. com/obra/milagros-de-nuestra-senora> [15/I/2008].

Castaños, Fernando, "Locos, muertos y ánimas en Pedro Páramo: los lugares de sus voces como rasgos de identidad", Discurso: teoría y análisis, revista del Instituto de Investigaciones Sociales de la UNAM, núm. 25, 2004, 43-63.

Castaños, Fernando, 2009 "Tú, llama Hamlet a sí: una reflexión sobre las transposiciones pronominales", en El "tercero": fondo y figura de las personas del discurso, R. Montes y P. Charaudeau (coord.), México, Benemérita Universidad Autónoma de Puebla, 45-55.

Cruz, sor Juana Inés de la, "Primero sueño" [1692], en Obras completas, I. Lírica personal, México, Fondo de Cultura Económica, 1951.

Cuesta, Jorge, "Canto a un dios mineral", en Mata, Rodolfo, "El fruto que del tiempo es dueño", Literatura mexicana, vol. 9, núm. 1, 1998, 131-137.

Darío, Rubén, Azul [1888], México, Porrúa, 2007.

GónGORA, Luis de, "Soledades" [1613], <www.cervantesvirtual.com/obra/soledades $>$ [15/I/2008].

González OchoA, César, A lo invisible por lo visible. Imágenes del Occidente medieval, México, Universidad Nacional Autónoma de México, 1995.

Gorostiza, José, "Muerte sin fin”, en Poesía [1964], México, Fondo de Cultura Económica, 1971.

HeIdegger, Martin, Sein und Zeit [1927], Tübingen, Max Niemeyer Verlag (Ser y tiempo, México, Fondo de Cultura Económica, 1951).

Lomnitz, Claudio, Death and the idea of Mexico [2005], New York, Zone Books (Idea de la muerte en México, México, Fondo de Cultura Económica, 2006).

Mallarmé, Stéphane, Un coup de dés jamais n'abolira le hasard [1897], Paris, Cosmopolis (Un golpe de dados jamás abolirá el azar, versión de Enán Burgos, Montpellier, Pleamar, 2010) <issuu.com/pleamar/docs/golpe_de_dados $>$ [15/I/2008].

MARLOWE, Christopher, "The tragical history of doctor Faustus from the quarto of 1604", en Works of Christopher Marlowe, vol. 3, USA, Amazon (formato Kindle), 2009. 
Milton, John, "Paradise Lost", en Works of John Milton, USA, Amazon (formato Kindle), 2008.

Nietzche, Friedrich Wilhelm, Die Fröhliche Wissenschaft Chemnitz: Verlag von Ernst Schmeitzner [1882] (La gaya ciencia, Madrid, Edaf, 2002).

Отно́n, Manuel José, "Idilio salvaje", en Antología de la poesía amorosa española y latinoamricana [1905], Víctor de Lama (comp.), Madrid, Edaf, 1993.

Paz, Octavio, "Muerte sin fin (José Gorostiza)", en Muerte sin fin y otros poemas [1951], México, Seix Barral, 1964,9-19.

Paz, Octavio, Piedra de sol, México, Fondo de Cultura Económica, 1957.

Platón, “Parménides”, en Diálogos, Madrid, Edaf, 1984.

PozAs, Ricardo, "La otra escritura: cultura y cambio social en los años sesenta". (En proceso de edición. La información respectiva se ha omitido en esta versión, para evitar la identificación del autor).

Quevedo, Francisco de, “iAh de la vida!” [1604], <www.franciscodequevedo. org. $>$ [15/I/2008].

Shakespeare, William, "Hamlet, Prince of Denmark", en The illustrated Stratford Shakespeare, Londres, Chancellor Press, 1982, 799-831.

Tablada, José Juan, Un día... Poemas sintéticos, Caracas, Imprenta Bolívar, $1919,<$ www.tablada.unam.mx/poesia.> [15/I/2008].

VEGA, Garcilaso de la, "Églogas" [1543], <www.garcilaso.org> [15/I/2008].

VEGA, Garcilaso de la, "Sonetos" [1543], <www.garcilaso.org> [15/I/2008]. 